\title{
Intramedullary Fixation of Diaphyseal Clavicle Fractures Using the Rockwood Clavicle Pin: Review of 86 Cases
}

\author{
William J. Marlow ${ }^{*}$, Peter Ralte, Syam PK Morapudi, Rashpal Bassi, Jochen Fischer and \\ Mohammad Waseem
}

Department of Trauma \& Orthopaedics, Macclesfield District General Hospital, Victoria Road, Macclesfield, SK10 $3 B L, U K$

\begin{abstract}
Aim: This study reports the safety, efficacy and functional and patient centred outcomes of the largest published series of patients treated with the Rockwood clavicle pin (intramedullary device) to date.

Patients and Methods: A retrospective review of case notes, radiographs and follow-up by questionnaire was conducted. 86 patients were operated upon, 70 for acute fractures (group A) and 16 for non-union (group B).

Results: Rate of non-union was 2 (2.9\%) in group A and 0 in group B. Mean Disability of the Arm, Shoulder and Hand (DASH) scores were 5.9 for group A and 8.7 for group B. Satisfaction was rated as good or excellent in 61 (96.8\%) of responders and all patients would have the procedure again. Pin prominence was the predominant complication in both groups and all patients underwent a second procedure for metalwork removal.

Discussion: Rockwood clavicle pins are as effective as plates in achieving union and maintaining length, however the advantages of this less invasive technique should be weighed against the common complication of pin prominence and the inconvenience of removal of metalwork in all cases.
\end{abstract}

Keywords: Clavicle [A02.835.232.087.227], Fracture Fixation, Intramedullary [E04.555.300.300.300], Fracture Healing [G16.100.856.891.500], Fractures, Malunited [C26.404.249], Fractures, Ununited [C26.404.468], Rockwood Clavicle Pin, Surgical Procedures, Minimally Invasive [E04.800].

\section{INTRODUCTION}

Fractures of the clavicle are common, accounting for $2.6 \%$ to $4 \%$ of adult fractures and $35 \%$ of injuries to the shoulder girdle [1-3]. Fractures of the shaft account for between $69 \%$ and $82 \%$ of all clavicle fractures $[1,3]$. Undisplaced fractures of the clavicle shaft often heal with good clinical outcomes following non-operative management and there is general consensus that these should be treated non-operatively [4]. Outcomes following non-operative management of displaced mid-clavicular fractures are far less favourable than was once perceived, with several studies observing increased rates of non-union and symptomatic malunion [5-8]. A meta-analysis of articles addressing the treatment of displaced mid-clavicular fractures between 1975 and 2005 revealed a $15.1 \%$ non-union rate for closed treatment, $2.2 \%$ with compression plating, and $2 \%$ with intramedullary fixation [8]. Residual disability as measured by deficits in shoulder strength and endurance, as well as reduced patient satisfaction have also been observed in non-operatively treated displaced clavicle shaft fractures [9]. A recent multicenter randomised prospective clinical trial has shown improved functional outcome, lower rates of non-union and malunion following operative treatment of displaced clavicle fractures [10]. Factors associated with non-union and the

*Address correspondence to this author at the Department of Trauma \& Orthopaedics, Macclesfield District General Hospital, Victoria Road, Macclesfield, SK10 3BL, UK; Tel: 016256613 15;

E-mail: WJMarlow@gmail.com development of long term sequelae following non-operative management of mid-clavicular fractures include displacement (in particular shortening of $>2 \mathrm{~cm}$ ), comminution and advancing age [8]. Internal fixation of clavicle fractures is most commonly performed with plating. Intramedullary fixation has been previously described using Knowles pins [11, 12], Kirschner wires [13], Hagie pins [14] and elastic intramedullary nails [15-17]. While fixation with a plate involves a significant scar over the fracture area to allow placement of screws along the plate's length, intramedullary fixation may be achieved with a much smaller scar at the fracture site and a second scar posterolaterally. The key evolutionary step between the Rockwood pin and previous intramedullary devices is that the threaded medial end and lateral locking nut allow both compression at the fracture site and resistance to migration of the metalwork. The purpose of this paper is to share the results of our experience with the Rockwood clavicle pin (DePuy, Warsaw, Indiana) in the treatment of acute diaphyseal clavicle fractures and non-union as an alternative to plate fixation.

\section{MATERIALS AND METHODOLOGY}

All cases of middle third clavicle fracture or non-union seen at one centre between February 2004 and February 2011 were included in the study. Of the 1086 cases, 985 patients were treated conservatively, $86(7.9 \%)$ were treated by intramedullary fixation using the Rockwood clavicle pin 
and $15(1.4 \%)$ underwent fixation with a plate. Indications for fixation were gross displacement of the fracture causing tenting of the skin, an open fracture or shortening by more than $20 \mathrm{~mm}$. Plate fixation was used in cases where the fracture extended proximally along the clavicle preventing the threaded medial end of the pin from gaining purchase, or distally preventing the locking nut from compressing the construct.

Of the 86 patients treated by Rockwood pin fixation, 70 $(81.4 \%)$ underwent Rockwood pin fixation acutely or subacutely within 16 weeks of the injury (group A). Cases treated subsequent to the 16 week point were considered as surgery for symptomatic non- or mal-union since union would be expected by this time (group B). The mean time to surgery was 18 (2-64) days in group A and 28.3 (4.0-240.7) weeks in group B. Delays to surgery in group A were the result of late presentation e.g. injury abroad, failed initial non-operative management due to subsequent fracture displacement, or polytrauma requiring initial treatment of more serious injuries.

Higher numbers of males underwent fixation in both groups - 53 vs 17 in group A and $13 v s 3$ in group B. The mean age was similar for each group -34.4 in the group A and 38.1 in group B. The dominant side was injured in around half of cases in each group. Fractures were classified according to the Edinburgh system [3]. Two raters (WJM \& PR) independently scored the radiographs and in the case of discrepancy, the senior author (MW) rated the radiograph for a third time. The most common subtype was 2B1 (Fig. 1A). In the group of patients treated by Rockwood pin fixation, the proportion of each sub-classification of fracture was similar to that seen in the group treated by plate fixation. 18 segmental 2B2 fractures were observed of which 17 were treated by Rockwood pin (Table 1).

Table 1. Fracture Classification: Proportion of Diaphyseal Clavicle Fractures Sub-Divided According to the Edinburgh Classification

\begin{tabular}{|c|c|c|}
\hline Classification & Group A & Group B \\
\hline \hline $2 \mathrm{~A} 1$ & $0(0 \%)$ & $3(18.8 \%)$ \\
\hline $2 \mathrm{~A} 2$ & $1(1.4 \%)$ & $0(0.0 \%)$ \\
\hline $2 \mathrm{~B} 1$ & $55(78.6 \%)$ & $10(62.5 \%)$ \\
\hline 2B2 & $14(20.0 \%)$ & $3(18.8 \%)$ \\
\hline
\end{tabular}

The mechanism of injury was varied with the highest proportion of patients in the acute group sustaining injuries from road traffic collision (RTC), particularly involving a motorcycle or bicycle. A similar range of mechanisms caused the injuries in the group B (Table 2).

All procedures were performed by three Consultant orthopaedic surgeons specialising in upper limb trauma, with the majority of cases $(79,92 \%)$ performed by the senior author.

Case notes and radiographs were retrospectively reviewed to facilitate fracture classification and assess the incidence of complications. Measurements of pre and post- operative clavicle lengths were conducted using the Picture Archiving and Communication System (PACS) to assess for

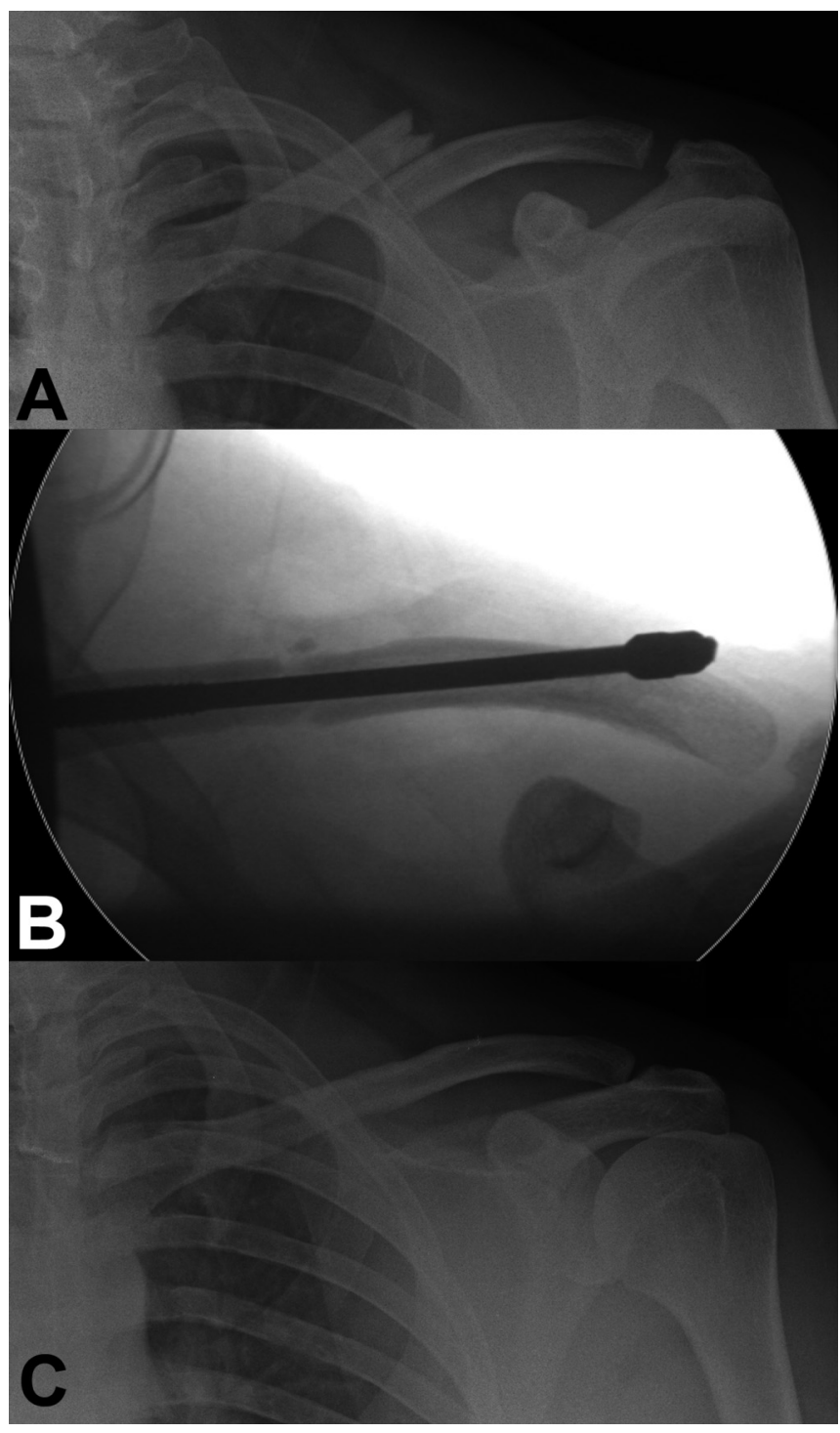

Fig. (1). Three consecutive AP radiographs showing: (A) Displaced comminuted acute mid shaft-clavicle fracture; (B) Intra-operative placement of the Rockwood Clavicle Pin; (C) United fracture, following pin removal, three months post-fixation.

correction of shortening using the following method. Postoperative radiographs were standardised using the known diameter of the pin used in that patient. True post-operative length of the clavicle was then calculated. A bony landmark was then measured on both the pre-and post-operative films and the pre-operative film was standardised to the postoperative one. The true pre-operative length was calculated. If there was rotational difference between films, length could not be calculated. Functional outcome and patient satisfaction were measured by means of the Disability of the Arm, Shoulder and Hand (DASH) outcome measure [18] and an overall procedure related satisfaction questionnaire. Significance of correction of shortening and difference in length of stay was analysed using Student's T-test. Statistics were calculated using Excel (Microsoft, WA USA). 
Table 2. Mechanism of Injury: Proportion of Injuries Caused by Each Mechanism

\begin{tabular}{|c|c|c|}
\hline Mechanism & Group A & Group B \\
\hline \hline Fall & $15(21.4 \%)$ & $6(37.5 \%)$ \\
\hline Sport & $26(37.1 \%)$ & $6(37.5 \%)$ \\
\hline Road traffic collision & $29(41.4 \%)$ & $425.0 \%)$ \\
\hline
\end{tabular}

\section{Surgical Technique}

The Rockwood clavicle pin was inserted as described in the manufacturer's technique manual [19]. Patients were placed in the beach chair position and following sterile draping, a $3 \mathrm{~cm}$ skin incision was made over the fracture site parallel to Langer's lines. The fracture was exposed by dividing the fibres of the platysma taking care to avoid injury to the middle branch of the supraclavicular nerve which usually lies just below it. Towel clips were used to grasp the medial and lateral fragments which were then sequentially drilled and tapped. The Rockwood pin was inserted antegrade into the lateral fragment using a Jacobs chuck and T-handle. The pin was then passed through the posterior cortex of the lateral fragment and exited through the skin via a small stab incision where it was retrieved laterally. Once the pin had retracted sufficiently into the lateral fragment, the fracture was reduced and the pin was passed retrogradely into the intramedullary canal of the medial fragment. Finally, two locking nuts were fitted to compress the fracture if needed, and to secure the pin laterally (Fig. 2). The Rockwood pins used in each group were of a similar size of median $3.8 \mathrm{~mm}$. Allomatrix Injectable Putty (Wright Medical Technology, Arlington, TN) was used in $20 \%$ of acute fractures in the presence of significant comminution and in $87.5 \%$ of cases in group B. The pin was then trimmed below the skin, and both incisions were sutured. All patients received prophylactic intravenous antibiotics at induction. Postoperatively patients were placed in a sling for 2 weeks. They were then instructed to resume activities of daily living as tolerated but avoid strenuous activities such as pulling, lifting or pushing and arm elevation higher than face level for 4 to 6 weeks. Patients were routinely listed for removal of Rockwood pin when there was clinical and radiological evidence of union 16 weeks postoperatively. Radiographic union was defined as the appearance of bridging callous. If there was evidence of delayed union, removal of the pin was postponed.

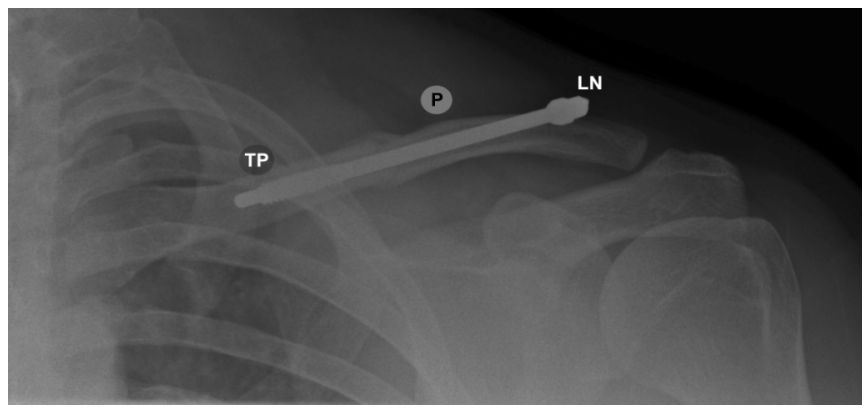

Fig. (2). Postoperative AP radiograph showing the Rockwood Clavicle Pin (P). The threaded pin tip (TP) is seen here secured in the medial fragment. Two locking nuts (LN) are fitted posterolaterally to compress and secure the fracture.

\section{RESULTS}

In group $\mathrm{A}$, the pins were removed at a mean of 3.6 months and follow-up was for a mean of 7.1 months. Functional assessments and satisfaction measures were carried out at a mean of 45 months. In group B, the pins were removed at a mean of 5.5 months and follow-up was for a mean of 8.7 months. Functional assessments and satisfaction measures were carried out at a mean of 34 months.

Sixty-eight fractures in group A went on to unite (Fig. 1A-C). The two cases of non-union were revised using a contoured locking plate and bone graft. There were no cases of non union in the group B although one case had not united at 8 months when the pin was removed - this was treated expectantly and united after a further 18 months (Table 3 ).

The predominant complication in both groups was posterior pin prominence causing significant irritation which resulted in wound oozing with or without superficial infection in several of the cases. Consequently four wounds in the acute group broke down exposing metalwork. Two of these underwent trimming at 14 and 48 days following pin insertion. The remaining two cases were managed expectantly with regular wound dressing until fracture union and pin removal. In all cases, symptoms of irritation resolved following hardware removal (Table 3 ).

One intra-operative complication was encountered which involved fracture of a drill tip while drilling the medial fragment. The broken tip was left in situ and due to its small size, no difficulties were encountered introducing or removing the pin following fracture union (Table 3 ).

Table 3. Complications: Rate of Complications in Each Group (Most Common First)

\begin{tabular}{|l|c|c|}
\hline \multicolumn{1}{|c|}{ Complication } & Group A & Group B \\
\hline \hline Pin prominence with irritation & $12(17.1 \%)$ & $3(18.8 \%)$ \\
\hline Wound oozing or infection & $8(11.4 \%)$ & $2(12.5 \%)$ \\
\hline Exposed metalwork & $4(5.7 \%)$ & $0(0 \%)$ \\
\hline Non-union & $2(2.9 \%)$ & $0(0 \%)$ \\
\hline Scar sensitivity & $1(1.4 \%)$ & $0(0 \%)$ \\
\hline Frozen Shoulder & $1(1.4 \%)$ & $0(0 \%)$ \\
\hline Chronic Pain & $1(1.4 \%)$ & $0(0 \%)$ \\
\hline Broken drill bit left in situ & $1(1.4 \%)$ & $0(0 \%)$ \\
\hline Deep Vein Thrombosis & $1(1.4 \%)$ & $0(0 \%)$ \\
\hline Delayed-union & $0(0 \%)$ & $1(6.3 \%)$ \\
\hline
\end{tabular}

The pre-operative shortening was corrected in the postoperative films by $8 \mathrm{~mm}$ in group A and $6 \mathrm{~mm}$ in group B. This was statistically significant in group A and showed a strong trend in group B (Table 4).

A reasonable response to $\mathrm{DASH}$ and satisfaction questionnaires was obtained $-71 \%$ in group $\mathrm{A}$ and $81 \%$ in group B. The mean DASH score was similar for both groups: 5.9 for group A and 8.7 for group B. All responders said they would have the procedure again and, although the 
vast majority of the acute group rated their satisfaction as good or excellent, $7.7 \%$ of group B rated their outcome as fair (Table 5).

Table 4. Correction of Shortening: Pre- and Post-Operative Clavicular Lengths Measured Radiologically. Statistical Significance Calculated Using a Paired TTest

\begin{tabular}{|c|c|c|c|c|}
\hline \multirow{2}{*}{} & \multicolumn{2}{|c|}{ Group A } & \multicolumn{2}{c|}{ Group B } \\
\cline { 2 - 5 } & $\begin{array}{c}\text { Mean } \\
\text { Length }\end{array}$ & Range & $\begin{array}{c}\text { Mean } \\
\text { Length }\end{array}$ & Range \\
\hline \hline Pre-op length (mm) & 127 & $83-157$ & 130 & $95-154$ \\
\hline Post-op length (mm) & 135 & $106-195$ & 136 & $114-156$ \\
\hline Gain in length (mm) & 8 & $-22-89$ & 6 & $-22-36$ \\
\hline p-Value & \multicolumn{3}{|c|}{0.001} & \multicolumn{3}{c|}{0.166} \\
\hline
\end{tabular}

Table 5. Functional and Satisfaction Outcomes: D.A.S.H. Scores, Proportion of Patients who would have Procedure Again and Satisfaction with Procedure

\begin{tabular}{|l|c|c|}
\hline & Group A (50) & Group B (13) \\
\hline \hline Mean D.A.S.H. Score & $5.9(0.0-60.0)$ & $8.7(0.0-35.0)$ \\
\hline $\begin{array}{l}\text { Patient who would have } \\
\text { procedure again }\end{array}$ & $100 \%$ & $100 \%$ \\
\hline $\begin{array}{l}\text { Patients rated satisfaction with } \\
\text { outcome of procedure as: }\end{array}$ & & \\
\hline Excellent & $42(84.0 \%)$ & $7(53.8 \%)$ \\
\hline Good & $7(14.0 \%)$ & $5(38.5 \%)$ \\
\hline Fair & $1(2.0 \%)$ & $1(7.7 \%)$ \\
\hline Poor & $0.0 \%$ & $0.0 \%$ \\
\hline
\end{tabular}

\section{DISCUSSION}

\section{Union}

2 cases of non-union were identified in group A. - one was at the start of the series and one four years later. The cases were performed at one and four weeks post injury. The rate of non-union of $2.9 \%$ in the acute fracture group is slightly lower than that previously seen for other intramedullary fixation (4.7\%) [20-25]. This rate is similar to the rate reported for plating of acute fractures $2.2 \%$ [8]. There were no episodes of malunion in this series, however, Mirzatolooei reported an incidence of $14 \%$ in plate fixation of acute fractures [26]. There were no cases of non-union in group B, reflecting a previous study by Lee [27], although there was one case of delayed union. In this case the clavicle was lengthened by $36 \mathrm{~mm} \mathrm{(35 \% )}$ and it is likely that the bone gap produced by this lengthening took longer to heal. A rate of $6.8 \%$ is seen following plating for non-union [28] possibly due to stripping of periosteum. This $100 \%$ rate of union in delayed fixation is promising; however the numbers in this study are too small to make a firm conclusion based on this.

\section{Complications}

There does appear to be a high rate of pin prominence and irritation for both acute and delayed groups, although, it should be noted that around $53 \%$ of patients with plate fixation go on to require plate removal for irritation, infection or prominence [22]. The $17.1 \%$ rate of irritation from pin prominence is higher than that seen by Kettler from fixation with elastic intramedullary nails (4.6\%) [16], however an equal number of elastic nails required early removal due to migration; migration was not seen with this device. Migration of elastic nails required secondary shortening in $16.1 \%$ of cases in a study by Mueller [15]. Hagie pins have been associated with an $18.8 \%$ rate of wound breakdown requiring debridement [14] which is higher than that seen in our study. The Rockwood pin may cause irritation if not cut sufficiently short, however its design appears to have reduced the risk of migration and thereby the risk of protrusion through the skin or into important structures in the vicinity [29].

Pin prominence was generally described by patients as a "mild to moderate irritation" and no patients required expedited pin removal on account of this. It should be noted that these symptoms universally resolved after hardware removal. All four cases of metalwork exposure and the majority of cases of pin prominence occurred before December 2006. This reduction in posterior pin prominence and metalwork exposure over the series was thought to be due to the introduction of a purpose-designed "Rockwood pin cutter" allowing the pin to be cut more flush to the bolts and modification of the surgical technique so that the pin exited the lateral end of the clavicle in a more inferior position, thus providing additional soft tissue coverage for the pin.

In this study, patients were mobilised at an early stage and returned to full activities at 4-6 weeks. There was no evidence of hardware failure or fatigue (seen with elastic nails [15]), even with $2.5 \mathrm{~mm}$ diameter pins.

Re-fracture following implant removal [30] and neurovascular and pulmonary injury from over drilling of the clavicle [31] have been reported in plate fixation, however these complications are avoided when using intramedullary fixation.

\section{Satisfaction}

DASH and satisfaction scores were generally good in both groups despite the high rate of complications. This probably reflects the fact that the majority of complications were caused by the pressure effect of a prominent pin and these resolved in all cases once the pin was removed. The DASH scores seen in this series were similar to those seen in patients treated by plate fixation $[26,32]$.

Cosmesis is an important factor, particularly in females. The Rockwood pin can be introduced through a $3 \mathrm{~cm}$ incision at the level of the fracture site, rather than a $6 \mathrm{~cm}$ incision required for a plate. This less invasive approach also reduces the risk to the supraclavicular nerve [33]. In the event of non-union requiring revision plating, the scar could be simply extended along Langer's lines although this series demonstrates this is an uncommon requirement. 
Removal of metalwork is required in all cases of intramedullary fixation compared to only half of the cases where the fracture is plated [22]. This is a key disadvantage of this technique, however while removal of a plate requires a general anaesthetic, the pin could potentially be removed under local anaesthetic in the clinic setting.

\section{Correction of Shortening}

A mean correction of shortening of $8 \mathrm{~mm}$ was demonstrated in group A when the pre- and post-operative films were compared which, although small, was statistically significant. The mean clavicle lengthening was smaller and non-significant in group B and this reflects the fact that several of the cases had previously been reduced with an attempt at fixation.

\section{LIMITATIONS}

Shortcomings of our study include the relatively small number of procedures performed and the short follow-up period. The retrospective nature of data collection, incompleteness of the functional outcome scores obtained and the lack of a control for comparison are also acknowledged. Despite this, our series is the largest of its kind and gives a robust picture of patient centred and clinical outcomes when using Rockwood clavicle pins.

\section{CONCLUSION}

Complications can be reduced by using purpose-designed Rockwood pin cutter, the use of bone graft in comminuted fractures and non-union, ensuring the lateral pin exit point is inferior and that the correction in shortening does not leave a void. There does appear to be a higher rate of irritation symptoms in patients with a slim build.

Rockwood pins appear to be as effective as plates in achieving union and maintaining length in both the acute and delayed setting with the advantages of smaller skin incisions and less periosteal disruption than a plate. Although they seemingly avoid the potentially catastrophic risks of migration seen in other intramedullary devices, the rate of pin prominence and need for a further procedure present a significant disadvantage. The $100 \%$ union rate in the delayed fixation group is promising, however the numbers in this group were small and an extended study is required to validate this. In choosing between plate and Rockwood pin fixation, one should weigh this less invasive technique against its potential for inconvenience and complications.

\section{ABBREVIATIONS}

DASH $=$ Disability of the Arm, Shoulder and Hand

PACS = Picture Archiving and Communication System

RTC $=$ Road Traffic Collision

\section{CONFLICT OF INTEREST}

There were no financial contributions to the work reported. The authors have no conflict of interest to declare.

\section{ACKNOWLEDGEMENTS}

The authors listed are responsible for production of this work from conception to final copy.

\section{REFERENCES}

[1] Postacchini F, Gumina S, De Santis P, Albo F. Epidemiology of clavicle fractures. J Shoulder Elbow Surg 2002; 11(5): 452-6.

[2] Nordqvist A, Petersson C. The incidence of fractures of the clavicle. Clin Orthop Relat Res 1994; 300: 127-32.

[3] Robinson CM. Fractures of the clavicle in the adult. Epidemiology and classification. J Bone Joint Surg Br 1998; 80(3): 476-84.

[4] Khan LA, Bradnock TJ, Scott C, Robinson CM. Fractures of the clavicle. J Bone Joint Surg Am 2009; 91(2): 447-60.

[5] Robinson CM, Court-Brown CM, McQueen MM, Wakefield AE. Estimating the risk of nonunion following nonoperative treatment of a clavicular fracture. J Bone Joint Surg Am 2004; 86-A(7): 1359-65.

[6] Hill JM, McGuire MH, Crosby LA. Closed treatment of displaced middle-third fractures of the clavicle gives poor results. J Bone Joint Surg Br 1997; 79(4): 537-9.

[7] McKee MD, Wild LM, Schemitsch EH. Midshaft malunions of the clavicle. J Bone Joint Surg Am 2003; 85-A(5): 790-7.

[8] Zlowodzki M, Zelle BA, Cole PA, Jeray K, McKee MD. Treatment of acute midshaft clavicle fractures: systematic review of 2144 fractures: on behalf of the Evidence-Based Orthopaedic Trauma Working Group. J Orthop Trauma 2005; 19(7): 504-7.

[9] McKee MD, Pedersen EM, Jones C, et al. Deficits following nonoperative treatment of displaced midshaft clavicular fractures. J Bone Joint Surg Am 2006; 88(1): 35-40.

[10] Canadian Orthopaedic Trauma Society. Nonoperative treatment compared with plate fixation of displaced midshaft clavicular fractures. A multicenter, randomized clinical trial. J Bone Joint Surg Am 2007; 89(1): 1-10.

[11] Zenni EJ Jr, Krieg JK, Rosen MJ. Open reduction and internal fixation of clavicular fractures. J Bone Joint Surg Am 1981; 63(1): 147-51.

[12] Neviaser RJ, Neviaser JS, Neviaser TJ. A simple technique for internal fixation of the clavicle. A long term evaluation. Clin Orthop Relat Res 1975; 109: 103-7.

[13] Ngarmukos C, Parkpian V, Patradul A. Fixation of fractures of the midshaft of the clavicle with Kirschner wires. Results in 108 patients. J Bone Joint Surg Br 1998; 80(1): 106-8.

[14] Strauss EJ, Egol KA, France MA, Koval KJ, Zuckerman JD. Complications of intramedullary Hagie pin fixation for acute midshaft clavicle fractures. J Shoulder Elbow Surg 2007; 16(3): 280-4.

[15] Mueller M, Rangger C, Striepens N, Burger C. Minimally invasive intramedullary nailing of midshaft clavicular fractures using titanium elastic nails. J Trauma 2008; 64(6): 1528-34.

[16] Kettler M, Schieker M, Braunstein V, Konig M, Mutschler W. Flexible intramedullary nailing for stabilization of displaced midshaft clavicle fractures: technique and results in 87 patients. Acta Orthop 2007; 78(3): 424-9.

[17] Jubel A, Andermahr J, Schiffer G, Rehm KE. Technique of intramedullary osteosynthesis of the clavicle with elastic titanium nails. Unfallchirurg 2002; 105(6): 511-6.

[18] Hudak PL, Amadio PC, Bombardier C. Development of an upper extremity outcome measure: the DASH (disabilities of the arm, shoulder and hand) [corrected]. The Upper Extremity Collaborative Group (UECG). Am J Ind Med 1996; 29(6): 602-8.

[19] DePuy International Ltd. Rockwood clavicle pin: design rationale and surgical technique. 2005: pp. 1-10.

[20] Chen YF, Zeng BF, Chen YJ, et al. Clinical outcomes of midclavicular fractures treated with titanium elastic nails. Can J Surg 2010; 53(6): 379-84.

[21] Bohme J, Bonk A, Bacher GO, Wilharm A, Hoffmann R, Josten C. Current treatment concepts for mid-shaft fractures of the clavicle results of a prospective multicentre study. Z Orthop Unfall 2011; 149(1): 68-76.

[22] Ferran NA, Hodgson P, Vannet N, Williams R, Evans RO. Locked intramedullary fixation $v s$ plating for displaced and shortened midshaft clavicle fractures: a randomized clinical trial. J Shoulder Elbow Surg 2010; 19(6): 783-9.

[23] Kleweno CP, Jawa A, Wells JH, et al. Midshaft clavicular fractures: comparison of intramedullary pin and plate fixation. $\mathrm{J}$ Shoulder Elbow Surg 2011; 20(7): 1114-7.

[24] Mudd CD, Quigley KJ, Gross LB. Excessive Complications of Open Intramedullary Nailing of Midshaft Clavicle Fractures With the Rockwood Clavicle Pin. Clin Orthop Relat Res 2011; 469: 3364-70. 
[25] Millett PJ, Hurst JM, Horan MP, Hawkins RJ. Complications of clavicle fractures treated with intramedullary fixation. J Shoulder Elbow Surg 2011; 20(1): 86-91.

[26] Mirzatolooei F. Comparison between operative and nonoperative treatment methods in the management of comminuted fractures of the clavicle. Acta Orthop Traumatol Turc 2011; 45(1): 34-40.

[27] Lee YS, Lin CC, Huang CR, Chen CN, Liao WY. Operative treatment of midclavicular fractures in 62 elderly patients: knowles pin versus plate. Orthopedics 2007; 30(11): 959-64.

[28] Shen JW, Tong PJ, Qu HB. A three-dimensional reconstruction plate for displaced midshaft fractures of the clavicle. J Bone Joint Surg Br 2008; 90(11): 1495-8.

[29] Sethi GK, Scott SM. Subclavian artery laceration due to migration of a Hagie pin. Surgery 1976; 80(5): 644-6.
[30] Poigenfurst J, Rappold G, Fischer W. Plating of fresh clavicular fractures: results of 122 operations. Injury 1992; 23(4): 237-41.

[31] Shackford SR, Connolly JF. Taming of the screw: a case report and literature review of limb-threatening complications after plate osteosynthesis of a clavicular nonunion. J Trauma 2003; 55(5): 840-3.

[32] Kabak S, Halici M, Tuncel M, Avsarogullari L, Karaoglu S. Treatment of midclavicular nonunion: comparison of dynamic compression plating and low-contact dynamic compression plating techniques. J Shoulder Elbow Surg 2004; 13(4): 396-403.

[33] Wang K, Dowrick A, Choi J, Rahim R, Edwards E. Post-operative numbness and patient satisfaction following plate fixation of clavicular fractures. Injury 2010; 41(10): 1002-5.

(C) Marlow et al.; Licensee Bentham Open.

This is an open access article licensed under the terms of the Creative Commons Attribution Non-Commercial License (http://creativecommons.org/licenses/by-nc/3.0/) which permits unrestricted, non-commercial use, distribution and reproduction in any medium, provided the work is properly cited. 